\title{
Estudo histológico de mamas de ratas castradas submetidas à terapêutica com esteróides sexuais
}

\author{
Histological study of the mammary glands of rats submitted to treatment with sex steroids \\ Autor: José Tadeu Vicelli \\ Orientadora: Prof ${ }^{\mathrm{a}}$. Dra ${ }^{\mathrm{a}}$. Maria Salete Costa Gurgel \\ Co-orientador: Prof. Dr. Marcelo Alvarenga
}

Tese apresentada ao Departamento de Tocoginecologia da Faculdade de Ciências Médicas da Universidade Estadual de Campinas (UNICAMP), para obtenção do título de Doutor, em 30 de maio de 2005.

\begin{abstract}
Objetivo: avaliar as alterações histológicas em mamas de ratas submetidas à terapêtica com estrogênio, progestogênio e tibolona. Métodos: estudo experimental com 40 ratas, sendo 20 sem prole (grupo A) e 20 com prole (grupo B). Todas foram castradas e, após quatro semanas, alocadas aleatoriamente em subgrupos: A1, A2, A3, A4, A5 e B1, B2, B3, B4, B5. Os esteróides foram administrados da seguinte forma: A1 e B1 - benzoato de estradiol; A2 e B2 - acetato de medroxiprogesterona; A3 e B3 - benzoato de estradiol e acetato de medroxiprogesterona; A4 e B4 - tibolona; A5 e B5 - placebo. Após dez semanas de tratamento, os animais foram sacrificados e suas glândulas mamárias submetidas à análise histológica. Os parâmetros avaliados foram: proliferação epitelial, atividade secretora e atipias epiteliais nas unidades de ductos ou alvéolos terminais. A associação entre os achados histológicos e os esquemas terapêuticos foi avaliada através do odds ratio e intervalo de confiança de 95\%.
\end{abstract}

\begin{abstract}
Resultados: alterações histológicas foram observadas em 29 ratas: hiperplasia moderada (52,5\%), hiperplasia alvéolo-nodular $(42,5 \%)$, atipia sem proliferação $(35 \%)$, hiperplasia leve $(32,5 \%)$, atividade secretora $(20 \%)$ e hiperplasia severa (5\%). Em ratas sem prole observouse 1,3 mais chances, em relação ao grupo-controle, de apresentar hiperplasia alvéolo-nodular no grupo que recebeu estrogênio, hiperplasia moderada no grupo tratado com progestogênio, e hiperplasia alvéolo-nodular e atipia sem proliferação epitelial com a associação entre estrogênio e progestogênio. Conclusões: hiperplasia moderada e atipia epitelial associaram-se à terapia combinada de estrogênio e progestogênio, e o antecedente de prole reduziu a ocorrência destas alterações e de hiperplasia alvéolo-nodular.
\end{abstract}

PALAVRAS-CHAVE: Mama; Proliferação epitelial; Esteróides sexuais; Atipia epitelial.

Resumo de Tese

\section{A acupuntura na reabilitação de mulheres após tratamento cirúrgico do câncer de mama}

\section{Acupuncture in the rehabilitation of women after surgical treatment of breast cancer}

Autora: Michele Elisabete Rubio Alem

Orientadora: Prof ${ }^{\mathrm{a}}$. Dra . Maria Salete Costa Gurgel

Tese apresentada ao Departamento de Tocoginecologia da Faculdade de Ciências Médicas da Universidade Estadual de Campinas (UNICAMP), para obtenção do título de Doutor, em 2 de dezembro de 2005.

\begin{abstract}
Objetivos: avaliar os resultados da acupuntura para reabilitação motora, diminuição do linfedema e melhora na percepção de aspectos gerais de vida em mulheres tratadas por câncer de mama. Método: foram estudadas, de fevereiro a dezembro de 2004, 29 mulheres submetidas a mastectomia radical ou quadrantectomia com esvaziamento axilar e que apresentavam linfedema e/ou diminuição na amplitude dos movimentos do ombro homolateral à cirurgia. Foram submetidas a 24 sessões semanais de acupuntura com permanência das agulhas por 30 minutos, totalizando seis meses de tratamento. Foi realizada uma avaliação prévia à intervenção para a determinação do linfedema e da restrição dos movimentos. Essas avaliações foram repetidas ao final de um, três e seis meses de tratamento. Antes e após seis meses de acupuntura, foi aplicado um questionário relativo à sensação de bem-estar, impacto da cirurgia sobre a vida, sono, atividades de vida diária, sensação de peso e repuxamento no membro superior afetado e para graduação destes parâme-
\end{abstract}

tros utilizou-se Escala Visual Analógica com variação de zero (muito bem) a dez (muito mal). A análise estatística foi realizada com uso do Teste de Friedman. Resultados: houve melhora nas limitações de amplitude dos movimentos de flexão e abdução do ombro e no grau do linfedema após seis meses de acupuntura ( $<<0,05)$. Quanto à circunferência de braço, antebraço e punho, não se observaram diferenças durante o tratamento. A percepção dos aspectos gerais melhorou após o tratamento: sensação de bem estar, impacto da cirurgia sobre a vida, sono, atividades de vida diária, sensação de peso e repuxamento no braço $(p<0,001)$. Conclusões: a acupuntura mostrou-se eficiente em todos os parâmetros avaliados, demonstrando ser uma alternativa terapêutica para reabilitação pós-cirúrgica no câncer de mama.

PALAVRAS-CHAVE: Câncer de mama; Acupuntura; Reabilitação 